\title{
80 anos de Serviço Social no Brasil: organização política e direção social da profissão no processo de ruptura com o conservadorismo
}

\author{
80 years of Social Work in Brazil: political organization and social \\ direction of the profession in the rupture process with conservatism
}

\author{
Maria Beatriz Costa Abramides \\ Doutora em Serviço Social pela PUC-SP, coordenadora do Neam - Núcleo de \\ Estudos e Pesquisas em Aprofundamento Marxista. São Paulo/SP, Brasil. \\ biabramides@gmail.com
}

\begin{abstract}
Resumo: O presente artigo se refere à trajetória histórica do Serviço Social brasileiro, considerada a direção social da profissão e o processo de ruptura com o conservadorismo. As determinações e os caminhos da profissão serão analisados a partir do projeto ético-político profissional hegemônico em sua relação com as lutas sociais e os direitos dos trabalhadores.
\end{abstract}

Palavras-chave: Projeto Ético-Político. Lutas sociais. Classe trabalhadora.

\begin{abstract}
This article refers to the historical trajectory of the Brazilian Social Service, considered the social direction of the profession and the process of rupture with conservatism. The requirements and profession paths will be analyzed from the ethical-political professional hegemonic project in its relationship with the social struggles and workers rights.
\end{abstract}

Keywords: Ethical-Political Project. Social struggles. Working class.

\section{I- Introdução}

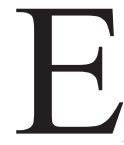

m 1916 comemora-se, no Brasil, os oitenta anos do Serviço Social, e com este artigo pretendo recuperar os traços constitutivos da direção social da profissão de ruptura com o conservadorismo. O ano de 1979 demarcou no III CBAS - Congresso Brasileiro de Assistentes Sociais, o conhecido "Congresso da Virada", sua expressão pública e coletiva. Tratarei dos antecedentes que o germinaram, dos determinantes de sua continuidade e dos desafios contemporâneos 
do Projeto Ético-Político profissional hegemônico do Serviço Social brasileiro PEP. Procuro resgatar a trajetória de combates e conquistas nos campos teórico, político, ético e organizativo dos profissionais como trabalhadores em sua condição de assalariamento inscritos na divisão sociotécnica do trabalho e em seu compromisso com a classe trabalhadora.

O artigo expressa o posicionamento das entidades de representação da categoria, na organização sindical (até os anos 1990), na formação e no exercício profissional e estudantil, em suas programáticas contra a ditadura militar, e no período de redemocratização do país contra as medidas de precarização no mundo do trabalho e do neoliberalismo, a partir de 1989, a serviço do capital. As entidades organizativas se materializam com autonomia e independência de classe em relação aos governos e ao patronato. Essa recuperação histórica se estabelece pela análise da realidade, do movimento das classes e do protagonismo histórico dos trabalhadores na direção do projeto societário de emancipação humana, ao qual o projeto profissional do Serviço Social brasileiro se vincula.

Analisar os oitenta anos da profissão, do ponto de vista da totalidade, pode abarcar vários e significativos aspectos para compreender a riqueza de sua concepção e prática profissionais. Minha escolha, porém, foi a de privilegiar as determinações e os caminhos da profissão consubstanciados no Projeto Ético-Político profissional hegemônico, do Serviço Social brasileiro, em sua relação com as lutas sociais e os direitos dos trabalhadores.

\section{$\|$ - Desenvolvimento}

\section{Como tudo principia}

A profissão, relativamente jovem, tem cinquenta de seus oitenta anos marcada pelo processo de ruptura com o conservadorismo. Isso não é pouca coisa em um país com a herança oligárquica, conservadora em seus processos de urbanização e industrialização. A divisão e a segregação de territórios nos grandes centros urbanos são expressões da desigualdade, constitutiva do modo de produção capitalista. A população empobrecida foi obrigada a se deslocar para as periferias com uma insuficiente rede de serviços públicos, de saneamento básico, poucos e precários transportes coletivos e viu como única opção ocupar as encostas de morros ou os 
fundos de vales para erguer sua morada, em um sistema precário de autoconstrução. Os trabalhadores rurais foram sendo expulsos do campo em razão da pobreza e da miséria, vieram para os grandes centros urbanos e se inseriram, em grande parte, em trabalhos sem regulamentação; outros foram absorvidos pela indústria nascente, no princípio do século XX. Até 2016, pouco se efetivou em relação à reforma agrária. Em sua maioria, não foram demarcadas as terras indígenas e quilombolas, uma dívida histórica para com as populações originárias.

Até os anos 1930, "a questão social" no Brasil era tratada como caso de polícia. Porém o governo ditatorial de Vargas, durante o Estado Novo, foi obrigado a regular as relações entre capital e trabalho, para o crescimento econômico do capitalismo e, consequentemente, para ampliar suas taxas de lucro. A gestão do capital, naquele momento, se estabelecera pela organização fordista-taylorista, de "produção em massa para consumo em massa", o que fez com que o Estado implementasse alguns programas sociais voltados para o consumo da população economicamente ativa, inserida no mercado formal de trabalho, e ao mesmo tempo incorporasse algumas reivindicações dos trabalhadores. Nessa lógica, implantou-se o sistema de previdência, de seguros, do salário mínimo e mecanismos reguladores da relação capital/trabalho. Foi criada a CLT — Consolidação das Leis do Trabalho, que estabeleceu a organização sindical no governo de Getúlio Vargas, a partir do modelo da Carta del Lavoro, do fascista italiano Benito Mussolini, que atrelou o sindicato ao Estado e acabou com a autonomia e a liberdade sindical.

A "questão social" já não podia mais ser tratada como "caso de polícia". Era preciso negociar com a classe operária que produz diretamente valor e mais-valia. Nesse sentido, o Estado promoveu a regulação das relações entre o patronato, a classe trabalhadora e entre outros mecanismos, e em 1936 foi criada a profissão de assistente social, que se institucionalizou somente em 1945. No período em que o Estado inicia o controle dos conflitos da contradição capital versus trabalho com o crescimento da classe operária na expansão do capitalismo, a profissão passou a atuar nas expressões da "questão social".

O primeiro curso de Serviço Social no Brasil foi fruto de um esforço coletivo de jovens mulheres engajadas na militância da Igreja Católica na cidade de São Paulo, em 1936. O curso ocorreu na antiga Escola de Serviço Social, da rua Sabará, bairro de Higienópolis, no período matutino. Em 1946, a Pontifícia Universidade Católica de São Paulo - PUC-SP foi fundada, e a Escola de Serviço Social a ela se agregou. Em 1971 foi incorporada como curso de Serviço Social da Facul- 
dade de Ciências Sociais e se transferiu para o campus Monte Alegre da PUC-SP. Em 1972 foi criado o primeiro mestrado, e em 1981 o primeiro doutorado, pioneiro na América Latina. Em 1982, constituiu-se em Faculdade de Serviço Social e, em 2006, com o redesenho institucional da PUC-SP, por meio do reagrupamento de cursos, retornou à Faculdade de Ciências Sociais.

O reconhecimento da "questão social", a racionalização e o controle do operariado, por parte do Estado, estavam presentes na ação das jovens pioneiras motivadas pela justiça social sustentada na doutrina social da Igreja. Alguns anos após a criação da Escola de Serviço Social foi fundada a Faculdade de Serviço Social São Paulo - FAPSS-SP - no mesmo prédio, no turno da noite, com jovens do sexo masculino que atuavam em instituições assistenciais e organizações filantrópicas não governamentais. Em 1971, a FAPSS-SP não se incorporou à PUC-SP e se manteve como faculdade isolada.

Em 1946 foi criada a Abess (Associação Brasileira de Ensino em Serviço Social), atual Abepss (Associação Brasileira de Ensino e Pesquisa em Serviço Social), momento em que várias escolas foram instaladas no país e organizados os primeiros projetos de formação profissional nos cursos de graduação. Em 27/8/1957 foi promulgada a primeira lei de regulamentação da profissão, e uma nova lei, de n. 8.662, foi sancionada em 7/6/1993, sob as bases de uma concepção de profissão voltada para as demandas e interesses da classe trabalhadora no processo de consolidação da ruptura com o conservadorismo.

2. Meados dos anos 1960 e seus determinantes

Em 15/5/1962 formou-se o conjunto CFAS/Cras (Conselho Federal de Assistentes Sociais e Conselho Regional de Assistentes Sociais), que, a partir de 1993, foi designado de conjunto CFESS/Cress (Conselho Federal de Serviço Social e Conselho Regional de Serviço Social), como entidades de fiscalização da profissão. Até os anos 1980, essas entidades foram dirigidas por profissionais de tendências tecnicistas e conservadoras, ocasião em que se estabeleceu um movimento de renovação no processo de democratização dessas entidades por meio de uma articulação, por todo o país, de profissionais de esquerda que atuavam no movimento sindical classista da categoria e estavam inseridos nos movimentos sindicais e populares. 
Pode-se afirmar que, até os anos 1970, três tendências se manifestavam no Serviço Social: a) a modernização conservadora, de orientação tecnicista e funcionalista, de manutenção do status quo; b) a desenvolvimentista e reformista dos anos 1950 e 1960; e c) a vertente da renovação da profissão. A renovação do Serviço Social brasileiro teve sua origem em meados da década de 1960 e apresentou três tendências: a) a modernizadora, alicerçada nos documentos de Araxá e Teresópolis, em que o Serviço Social é concebido como instrumento de intervenção a ser operacionalizado nos marcos de manutenção do capitalismo; b) a reatualização do conservadorismo, cuja concepção se assentava na fenomenologia pela autorrepresentação da profissão, rejeição ao positivismo, presente na tradição modernizadora, e a teoria social de Marx; c) a terceira se expressou no legado marxiano e na tradição marxista por meio do projeto de intenção de ruptura com o conservadorismo, que conquistou sua hegemonia a partir de 1979.

\section{Processo de ruptura com o conservadorismo}

\subsection{A gênese}

\section{a) A experiência do Método $\mathrm{BH}$ - 0 legado da reconceituação}

A gênese do projeto de intenção de ruptura (Netto, 1991) teve sua emersão em 1966 com o movimento de reconceituação na América Latina, considerada a primeira aproximação do Serviço Social com a tradição marxista, que estabeleceu uma crítica ao Serviço Social tradicional e propôs um novo projeto de formação profissional. A efervescência do movimento de reconceituação possibilitou a solidariedade às lutas de resistência contra as ditaduras com violenta repressão no continente.

O movimento de reconceituação incidiu no Brasil no projeto pioneiro de formação profissional da Escola de Serviço Social da Universidade Católica de Minas Gerais. Conhecido como método BH, sua formulação e experiência se desenvolveram entre 1972 e 1975. Valeram-se da teoria social de Marx e do materialismo histórico e dialético na compreensão do significado social da profissão, das contradições e antagonismos da sociedade capitalista de exploração da força de trabalho, na direção de uma nova sociabilidade humana. 


\section{b) 0 movimento estudantil de Serviço Social no período da ditadura no Brasil}

Outro aspecto a ser considerado no processo de ruptura com o conservadorismo, e pouco estudado, foi a forte atuação do movimento estudantil em Serviço Social após o golpe militar de 1964 e que se estendeu até 1968. A partir do decreto do AI-5, em 13/12/1968, a repressão se ampliou com o cerceamento aos instrumentos de luta, como os sindicatos, os movimentos populares, estudantil e rural. Militantes foram exilados e, a partir de 1971, de forma mais extensiva, muitos foram torturados e mortos.

Em âmbito nacional, a organização dos estudantes de Serviço Social se expressou na Eness (Executiva Nacional de Estudantes de Serviço Social) na UNE (União Nacional de Estudantes). Durante seu congresso, em julho de 1968, em Fortaleza (CE), a assembleia de estudantes aprovou uma tese defendida pelo setor hegemônico militante na APML (Ação Popular Marxista Leninista), uma das muitas organizações clandestinas de esquerda existentes no período. A tese sustentava que a profissão deveria ter como referência a realidade brasileira e sua inserção no modo de produção capitalista para a formação e o exercício profissional; expressava ainda os direitos e lutas sociais sufocados pela forte repressão da ditadura militar e o compromisso com os trabalhadores.

Empreendiam a luta contra o Acordo MEC-Usaid, a Lei Suplicy de Lacerda e o Decreto n. 477, que postulavam a reforma do ensino superior brasileiro baseada no modelo americano para os países subordinados do Terceiro Mundo: cursos de curta duração, educação a distância, com orientação tecnicista, além de conteúdos da ideologia da segurança nacional impostos pela ditadura militar; expulsão de estudantes que atuavam politicamente e proibição da organização política nos CAS, DCES livres, Uees e UNE colocados na ilegalidade. A defesa da aliança operário-camponesa estudantil na luta contra a ditadura, contra o imperialismo, contra o capitalismo, na perspectiva da revolução social, fez com que estudantes exercessem a solidariedade ativa por ocasião das greves operárias de Osasco (SP) e Contagem (MG), em julho de 1968. O movimento estudantil participou efetivamente das atividades culturais como o CPC (Centro Popular de Cultura) da UNE e da ambiência cultural de forte contestação. ${ }^{1}$ Algumas experiências de debates

1. São desse período as peças teatrais: Eles não usam black-tie, Arena conta zumbi, Arena conta Tiradentes, Morte e vida severina, Gracias señor, Feira paulista de opinião, Liberdade liberdade, Gota d'água, 
críticos à formação profissional tecnicista e conservadora foram apresentados no congresso de Fortaleza.

Resgato umas das experiências: em 1968, os estudantes da Escola de Serviço Social da PUC-SP paralisaram as aulas por três meses juntamente com os professores e debateram um novo projeto de formação profissional. Alguns professores, ao voltarem do encontro de Teresópolis, apresentaram a metodologia da intervenção baseada em "variáveis e funções", denominadas "situações sociais problemas". A vanguarda do movimento estudantil, por influência da corrente marxista na militância política, criticou a vertente funcionalista e tecnicista, debateu a importância dos campos de estágios junto à população trabalhadora, incorporou o método Paulo Freire na pedagogia da ação profissional e defendeu a participação paritária nas instâncias colegiadas entre professores, estudantes e funcionários.

No período de 1969 a 1977, após o decreto do AI-5, em 13/12/1968, ocorreram prisões, desaparecimentos, torturas, assassinatos, exílios, cerceamento das entidades sindicais, estudantis e populares. Muitos estudantes e assistentes sociais viveram na clandestinidade, foram exilados, presos, torturados, e no período da luta pela redemocratização atuaram fortemente pela anistia e outras frentes de lutas sociais e se tornaram quadros expressivos no processo de ruptura da profissão com o conservadorismo.

A participação dos estudantes em Serviço Social no congresso da UNE foi debatida no congresso da Eness para que as escolas elegessem representantes, o que culminou com a expressiva participação no XXX Congresso da UNE. Das 152 jovens mulheres presas em Ibiúna, 25 eram estudantes de Serviço Social. Para aprofundar os elementos de ruptura desse período, torna-se necessária a elaboração de pesquisas, que ainda eram muito escassas e pouco presentes, na literatura do Serviço Social brasileiro.

\footnotetext{
Roda viva. Essa última peça sofreu uma "invasão" pelo CCC (Comando de Caça aos Comunistas) e os estudantes em geral e os de Serviço Social imediatamente se dirigiram ao teatro em defesa da liberdade de expressão e manifestação. São desse período as músicas de contestação de Chico Buarque de Holanda, Geraldo Vandré, Edu Lobo, Sérgio Ricardo. Por ocasião da prisão dos mil estudantes, no XXX Congresso da UNE, em Ibiúna, os jovens, entre o local do evento e os ônibus e caminhões que os levariam para o presídio, percorreram a pé cerca de catorze quilômetros cantando o hino da resistência "Pra não dizer que não falei de flores", de Geraldo Vandré.
} 


\subsection{Continuidade do processo de ruptura}

a) Sindicalismo combativo e de lutas da categoria dos assistentes sociais

Um aspecto decisivo do processo de ruptura com o conservadorismo se localizou no vigoroso movimento sindical dos assistentes sociais, nos marcos de um sindicalismo de lutas que irrompia a conjuntura do país.

A partir da falsificação dos índices do custo de vida, anunciados pelo então ministro da Fazenda da ditadura militar, Delfim Netto, em 1977, iniciou-se um movimento sindical classista com as grande greves operárias no ABC paulista em 1978 - Scania, Ford, Volks, Villares. Mercedes, Pirelli, Cofap, Philips, entre outras o que reacendeu a luta pela ação direta, de organização democrática, e pela base. Na ditadura militar, o Mosmsp (Movimento de Oposição Sindical Metalúrgica de São Paulo) empreendeu uma luta de resistência em relação ao maior sindicato de operários da América Latina, o Sindicato dos Metalúrgicos de São Paulo. Métodos de ação direta, imprensa operária e comissões de fábrica foram centrais para a retomada do sindicalismo classista (Batistoni, 2014). Esse movimento sindical que renascera foi denominado Novo Sindicalismo. ${ }^{2}$

A efervescência sindical no movimento operário se expandiu para outras categorias de trabalhadores que retomaram seus sindicatos e associações pré-sindicais. Entre esses trabalhadores estavam os assistentes sociais, com um amplo processo de organização e lutas.

A categoria dos assistentes sociais, em 1978, realizou seu primeiro encontro com a presença de quatro entidades: as Apas (Associação Profissional dos Assistentes Sociais) de São Paulo, Bahia e Goiás e o Sindicato de Minas Gerais, que impulsionaram um amplo processo de rearticulação das entidades sindicais no país. Vincularam-se à Anampos (Articulação Nacional dos Movimentos Populares e

2. A denominação Novo Sindicalismo, no final dos anos 1970, advinha da contraposição ao sindicalismo pelego, de sustentação da ordem do capital e da ditadura. É importante, porém, lembrar que o sindicalismo combativo esteve presente em toda a trajetória do sindicalismo durante o século XX, por meio do anarcossindicalismo, dos socialistas, comunistas, trotskistas, das pastorais operárias (vinculadas à Teologia da Libertação), e desenvolveram uma ação sindical classista e de lutas. Portanto, não se trata de um novo sindicalismo, posto que o sindicalismo classista de outrora estava sendo retomado nesse momento após anos de repressão ao movimento sindical. Essa designação passa a ter influência na teoria dos chamados "novos movimentos sociais", que questionam os movimentos clássicos da classe, o sindicato e o partido. 
Sindicais), do polo combativo de lutas dos trabalhadores que fundou a CUT (Central Única dos Trabalhadores), em 1983, e o MST (Movimento dos Trabalhadores sem Terra), em 1984.

Por outro lado, as entidades sindicais da categoria profissional atuaram diretamente na organização dos trabalhadores em serviço público e junto com outros sindicatos de categorias, como médicos, enfermeiros, sociólogos, psicólogos. Participaram ativamente de campanhas salariais e greves nesse ramo de atividade. ${ }^{3}$ No período de 1977 a 1988, os sindicatos de categorias profissionais tiveram um papel fundamental na luta dos trabalhadores em serviço público. Em 1979, 62,5\% dos profissionais atuavam nas esferas municipal, estadual e federal, de acordo com dados do Dieese (Departamento Intersindical de Estudos Socioeconômicos); em 1995, conforme pesquisa do CFESS, 78,16\% da categoria permanecia ali empregada. Até hoje a maioria dos profissionais se inscreve nos espaços sócio-ocupacionais do serviço público. A partir de 1988, os assistentes sociais se organizaram nos sindicatos de ramo dos trabalhadores em serviço público por contratação, a exemplo dos sindicatos municipais ou por área de atividade, como os sindicatos da Saúde e da Previdência nas esferas estadual e federal.

Entre 1977 e 1988, os sindicatos de categoria cumpriram um papel classista e de lutas, mas era necessário avançar, com a extinção desses sindicatos e a inserção nos sindicatos por ramo de atividade econômica. Isso ocorreu de 1988 a 1992, com o término da Anas (Associação Nacional Sindical dos Assistentes Sociais), nossa legítima federação, livre e autônoma.

No período da retomada das entidades sindicais de assistentes sociais, de 1977 a 1979, a categoria se reconheceu como parte da classe trabalhadora, em sua condição de assalariamento, por sua inserção na divisão sociotécnica do trabalho; participou da reorganização do movimento sindical classista e atuou junto aos movimentos populares sobre o custo de vida, contra a carestia, pelo SUS (Sistema Único de Saúde), feminista, de luta por creches, moradia, estudantil, negro unificado, além do apoio e solidariedade às lutas dos trabalhadores sem terra, quilombolas e indígenas.

3. Os trabalhadores em serviço público eram proibidos por lei de ter seus sindicatos. Assim, organizavam-se em associações, mas com pouco poder de negociação face ao Estado. A estrutura sindical previa a organização de sindicatos de categorias, dos chamados "profissionais liberais", aqui entre aspas, posto que, longe de serem liberais, constituem-se fundamentalmente como assalariados; a maioria se encontrava entre os assistentes sociais. 
b) 0 divisor de águas: o "Congresso da Virada" — III CBAS em 1979

O exercício profissional dos assistentes sociais esteve diretamente vinculado às lutas por direitos sociais e trabalhistas, a partir de 1977, e foi amplamente debatido em nossas entidades sindicais, como tema dos CBAS, a partir do "Congresso da Virada", em 1979. A vinculação ao movimento sindical e popular criou uma referência de organização política aos profissionais para que o encontro das 29 entidades sindicais e pré-sindicais, rearticuladas em um curto espaço de dois anos, possibilitasse que dirigentes sindicais, sob a coordenação da Ceneas (Comissão Executiva Nacional das Entidades Sindicais), atuassem no III CBAS com uma estratégia política. Dirigentes sindicais participaram do congresso nos grupos de trabalho e puderam perceber a insatisfação dos participantes mediante a estrutura burocrática; a presença de representantes da ditadura militar na mesa de abertura; a fragmentação dos debates; o número reduzido dedicado à participação estudantil. Isso fez com que a partir do segundo dia o congresso passasse a ser dirigido pelas entidades sindicais coordenadas pela Ceneas, com assembleias diárias que alteraram toda a lógica estabelecida. A plenária de encerramento selou o compromisso da profissão com a classe trabalhadora e homenageou todos que lutaram contra a ditadura no país (Abramides e Cabral, 1995).

O III CBAS se transformou na expressão pública e coletiva do processo de ruptura com o conservadorismo, cuja inflexão se materializou no reconhecimento dos assistentes sociais como trabalhadores em sua condição de assalariamento, no compromisso profissional com os direitos e conquistas históricas da classe trabalhadora, na práxis profissional vinculada às demandas concretas dos trabalhadores e aos movimentos sociais, na articulação da Ceneas, sindicatos e Apas com a Abess, que iniciara a construção de um novo currículo sustentado na teoria social de Marx, na defesa do serviço público de qualidade, na luta pela democratização das instituições, na articulação do projeto profissional ao projeto societário contra a exploração e opressão, na articulação com o movimento estudantil de Serviço Social que se reorganizara, no estabelecimento de uma estratégia entre os assistentes sociais que se inseriam nos sindicatos, movimentos sociais, universidades, práxis profissionais, vinculados à perspectiva marxista, no sentido de disputar as direções dos Cras e CFAS que estavam sob a hegemonia da modernização conservadora e dos tecnicistas; na retomada da articulação latino-americana por meio da Alaets e Celats; na ação conjunta da Ceneas, Abess, Sessune (Subsecretaria de Estudantes de Serviço Social na UNE) no período de 1979 a 1982; na incorporação do conjunto 
CFAS/Cras no IV CBAS em 1982, já parcialmente renovado pelo processo de democratização, que se ampliou na década de 1990. A esse conjunto de determinações denominamos "direção social da profissão".

c) A direção social da profissão: final dos anos 1970 e os anos 1980

A configuração da direção social da profissão pela ruptura do conservadorismo se alastrou por meio de muitas expressões, a saber:

c1) Experiências profissionais pautadas pelo movimento de reconceituação:

- O trabalho social desenvolvido no Inocoop-SP - Instituto de Orientação às Cooperativas Habitacionais, de 1977 a 1979, com cooperativas e moradores de núcleos habitacionais que se organizaram por meio de experiências de representantes de rua; organização condominial nos conjuntos habitacionais; associações de moradores com métodos democráticos e de participação direta, que culminou na criação da primeira associação autônoma nacional de mutuários na luta pela habitação e que questionou o financiamento habitacional, a ausência de equipamentos e serviços sociais, a precarização da construção e o favorecimento das empreiteiras e construtoras que se beneficiaram financeiramente nesse processo. Face a esse trabalho, a equipe de profissionais foi demitida, apesar da luta de resistência dos cooperativados, mutuários e moradores contra essa medida de cerceamento de uma ação combativa e crítica dos trabalhadores e participantes do processo de habitação social (Abramides, Mazzeo, Fingermann, 1984).

- Experiência do trabalho profissional na Sebes (Secretaria de Bem-Estar do Município de São Paulo), de 1981 a 1984. A mesma se efetivou pela atuação interdisciplinar nas macrorregiões territoriais periféricas de São Paulo e na região central junto aos moradores de cortiços. Os programas Mobral (Movimento Brasileiro de Alfabetização de Adultos), "Menor" (assim denominado à época pelo pensamento conservador) e Habitação se estruturaram setorialmente; porém, o trabalho profissional rompeu com essa lógica e se implantou a partir do território, nas favelas e cortiços, tratando coletivamente das demandas por habitação, creche, transportes, saúde, em uma ação integrada, de totalidade da realidade social (Raichelis, 
1998). Essas experiências profissionais nos marcos da renovação, na vertente de intenção de ruptura, possuem muitos documentos de referência para futuras pesquisas.

c2) Legado dos assistentes sociais na luta sindical

- A luta específica pela estruturação da carreira profissional, por reposição salarial, salário igual para trabalho igual; a luta por condições de salário, trabalho e carga horária dos assistentes sociais, que culminou com um projeto de lei que previa a jornada de trinta horas semanais e um piso salarial de dez salários mínimos (aprovado no Congresso Nacional e vetado pelo presidente Sarney); o levantamento da inserção dos assistentes sociais no mercado de trabalho; a luta e a conquista pela justa posição de cargos e carreiras dos assistentes sociais no serviço público federal; a luta contra as demissões de profissionais que implementavam um projeto profissional voltado para os interesses populares.

- A luta pela reorganização sindical e deliberação unânime de construir os sindicatos por ramos de atividade e neles se inserir; extinção dos sindicatos de categoria e da Anas, no período de 1988 a 1992, conforme deliberação do II Congresso da CUT, em 1986; participação efetiva na organização dos trabalhadores em serviço público, em que a categoria se inseriu centralmente.

- A luta mais geral da classe contra a ditadura, anti-imperialista, anticapitalista e socialista; solidariedade ativa aos movimentos grevistas; contra o pagamento da dívida externa; pela anistia ampla, geral e irrestrita; luta por uma assembleia nacional constituinte livre, soberana e democrática e eleições diretas.

- A luta junto aos movimentos populares por creches diretas, saúde pública, estatal, gratuita, universal; transporte coletivo de qualidade, educação pública, laica, gratuita, universal em todos os níveis, contra o decreto do município de São Paulo, de n. 15.086, que postulava que os assistentes sociais deveriam retirar, juntamente com a polícia, os moradores das favelas ocupadas, e mediante a luta de resistência dos moradores e da Apassp o projeto foi engavetado. Desse processo originou-se o MUF (Movimento Unificado de Favelas) (Singer, 1980). 
c3) Legado marxiano e tradição marxista na produção acadêmica e intelectual

- Publicação do livro Serviço Social e relações sociais no Brasil, de Marilda Vilela Iamamoto e Raul de Carvalho, em 1982, a primeira obra na literatura do Serviço Social brasileiro, com referência no legado marxiano e na tradição marxista. Constituiu-se em um clássico para a profissão, e a partir dessa obra ampliou-se a literatura do Serviço Social nessa orientação teórico-metodológica.

- Elaboração do currículo de 1982 pela Abess, com ampla participação das unidades de ensino, que definiu um projeto pedagógico de formação profissional que apresentou como pressupostos: a teoria social em Marx; o trabalho como categoria fundante do ser social; as múltiplas determinações do capitalismo monopolista; a ruptura com o positivismo, o funcionalismo e o ecletismo; a adoção do pluralismo; a profissão inscrita na divisão sociotécnica do trabalho e os assistentes sociais como trabalhadores, em sua condição de assalariamento; a direção social da profissão, articulada à perspectiva emancipatória. Apesar desses fundamentos, ocorreram lacunas nesse currículo, pela separação entre história, teoria e método e insuficiente apreensão da totalidade social que só serão superadas com as diretrizes curriculares de 1996.

c4) A organização da categoria - o conjunto CFAS/CRAS (atual conjunto CFESS/CRESS)

Até o final dos anos 1970, esse conjunto, voltado ao exercício profissional, era dirigido por setores tecnicistas e/ou conservadores. A partir do "Congresso da Virada", os profissionais de esquerda da profissão iniciaram, de forma articulada, uma mobilização que culminou, na década de 1980 e princípio da de 1990, na renovação de seus dirigentes inscritos na vertente do processo de ruptura com o conservadorismo. É na efervescência política, acadêmica, teórica, sindical e organizativa que se construiu o Código de Ética Profissional de 1986, no fórum do conjunto CFAS/CRAS, em que, pela primeira vez, os participantes têm a hegemonia marxista e a possibilidade de ruptura com o conservadorismo. O Código de Ética apresentou, porém, uma série de lacunas devido ao pouco amadurecimento teórico-filosófico que pudesse discernir a dimensão ética da dimensão política da profissão, que se articulam, mas possuem natureza própria, e sua superação se fará com o Código de 1993 (Barroco, 2001). 


\subsection{Consolidação do processo de ruptura com o conservadorismo}

a) Conjuntura da década de 1990 e dezesseis anos dos anos 2000

O capital apresentou sua crise estrutural no plano internacional a partir de 1973, decorrente da queda tendencial das taxas de lucro e de superprodução. Para recuperar seus patamares de acumulação, estabeleceu novas ofensivas sobre a classe trabalhadora: no mundo do trabalho, implantou a "acumulação flexível” (Harvey), que ampliou a exploração da força de trabalho, bem como os ritmos; impôs o desemprego estrutural, acentuou o trabalho precário, temporário, parcial, terceirizado; ocorreu um fechamento e realocação das indústrias, com menores salários e menos impostos aos empresários. Na esfera política, o Estado implementou o neoliberalismo por um conjunto de contrarreformas, privatizações, destruição de direitos sociais e trabalhistas, ajuste fiscal e consequente redução orçamentária nos programas sociais.

$\mathrm{Na}$ América Latina, o neoliberalismo foi firmado por meio do Consenso de Washington, em 1989, como programática do FMI (Fundo Monetário Internacional), do BM (Banco Mundial) e da OMC (Organização Mundial do Comércio), no processo de internacionalização do capital e de seus ajustes. Trata-se de uma crise estrutural do capital (Mézsáros), sistêmica (Netto), para que se estabeleçam novos padrões de acumulação. A ideologia dessa programática se baseia na "pós-modernidade" como ofensiva de subordinar cada vez mais os trabalhadores à lógica do domínio do capital como indestrutível e perene.

No Brasil, mal a Constituição saíra do forno, em 1988, no governo Sarney, em 1989 se iniciaram as primeiras investidas do neoliberalismo, implantadas no governo Collor de Mello, estendidas no governo Itamar Franco, aprofundadas e consolidadas nos dois mandatos de Fernando Henrique Cardoso, nos dois governos de Lula da Silva e ao longo do governo Dilma.

As contrarreformas do Estado, da Previdência, do ensino superior, sindical e trabalhista, as privatizações, os ajustes fiscais para o pagamento da dívida pública e deslocamento para a esfera privada ocorreram no governo FHC e prosseguiram nos de Lula e Dilma, com exceção da contrarreforma do Estado constituída no governo FHC. Em que pesem os programas sociais desenvolvidos nos governos de Lula e Dilma, voltados para as massas mais pauperizadas do país, ao não se vincularem a políticas sociais estruturantes, reproduzem o ciclo da desigualdade, apesar da redução da miséria absoluta. 
b) 0 Serviço Social nos anos 1990 e 2000 — uma década e meia

\section{b1) Considerações introdutórias}

Uma das questões centrais do projeto profissional se voltou para a luta contra o neoliberalismo, que pressupõe "um combate ético, teórico, político e prático-social ao neoliberalismo e aí reside o futuro do projeto ético-político profissional" (Netto,1999, p. 15, grifos nossos). Esse combate tem se consolidado em nossos congressos, na agenda política das entidades da categoria, na formação profissional, na produção acadêmica e intelectual, em experiências profissionais que têm se mantido na defesa intransigente dos direitos sociais e de apoio às lutas concretas dos movimentos sociais, sindical e populares contra a exploração no trabalho e a opressão e dominação de classe, na direção emancipatória.

As entidades da categoria se mantiveram em sua autonomia em relação ao Estado, aos governos e ao patronato em todo o processo de ruptura. Essa observação é fundamental, posto que muitas entidades e movimentos sociais se tornaram governistas a partir do governo Lula, a exemplo da CUT, da UNE e da direção majoritária do MST, além de um conjunto de sindicatos que se transformaram em sindicatos "cidadãos" de colaboração de classe. Esse giro tem trazido um processo de atraso à classe trabalhadora. Muitos movimentos sociais específicos de mulheres, negros, moradia têm se voltado para suas reivindicações imediatas, mais que necessárias, porém desvinculadas da questão de classe, o que tem levado a uma fragmentação e à atomização das lutas.

b2) O Projeto Ético-Político Profissional do Serviço Social brasileiro

O PEP, assim denominado nos anos 1990, é a expressão madura de consolidação da direção social da profissão dos anos 1980, que se estabeleceu no processo de ebulição da luta de classes no país em que os profissionais estiveram organicamente vinculados à classe trabalhadora. Portanto, as condições políticas de constituição do PEP do Serviço Social brasileiro devem ser avaliadas considerando as seguintes determinantes: a luta contra a ditadura, a colagem aos movimentos sociais dos anos 1980, a mudança do público profissional composto pelas camadas médias e empobrecidas, e como as vanguardas profissionais e acadêmicas da categoria são vanguardas de militância política e sociais (Netto, 1999; Abramides, 2006).

As bases do PEP são, respectivamente, o Código de Ética Profissional de 1993, a Lei de Regulamentação da Profissão de 1993, e as Diretrizes Curriculares de 1996. 
Nesse processo, do ponto de vista da organização sindical, ocorreu a dissolução dos sindicatos e da Anas.

\section{- 0 Código de Ética de 1993}

Esse código superou algumas lacunas do de 1986, ao estabelecer sua dimensão histórico-ontológica, que formulou uma direção estratégica que se contrapôs à lógica do domínio do capital; reconheceu a liberdade como valor ético central e de autonomia, expansão e plena emancipação dos indivíduos sociais; contrapôs-se a todas as formas de preconceito e estabeleceu sua opção por um projeto profissional articulado a uma nova ordem societária, sem exploração, dominação e opressão social de classe, gênero, raça, etnia, faixa etária e orientação sexual. Os princípios do Código de Ética são norteadores da formação e do exercício profissional.

- A Lei de Regulamentação da Profissão — 7/6/1993

Revista e atualizada, essa lei refere-se ao exercício profissional, às competências e atribuições privativas dos assistentes sociais e dos Cress, na qualidade de órgãos fiscalizadores da profissão. As competências profissionais direcionam-se fundamentalmente aos direitos civis, políticos e sociais, no atendimento aos sujeitos sociais de direitos. Para que os profissionais possam desenvolver o projeto ético-político, torna-se necessário estabelecer uma análise permanente da realidade que se constitui no solo histórico da formação e do exercício profissional.

- As Diretrizes Curriculares de 1996

São expressão de um debate articulado pela Abepss com as unidades acadêmicas para superar as lacunas do currículo de 1982. A LDB (Lei de Diretrizes e Bases), em 1996, acabou com currículos e os substituiu por diretrizes, como parte da "flexibilização" prevista na contrarreforma da educação. Porém foram mantidos nos projetos curriculares os conteúdos definidos nos fóruns da Abepss, em que se reafirmou a profissão fundada no movimento da realidade, considerados o legado marxiano e a tradição marxista; a totalidade da teoria social de Marx; o trabalho como categoria fundante do ser social; a profissão inscrita na divisão sociotécnica do trabalho; o assistente social como trabalhador coletivo em sua condição de assalariamento; a função social da profissão; a articulação e a indissociabilidade das dimensões teórico-metodológicas, ético-políticas e técnico-operativas; unidade 
teoria e prática como práxis profissional e a articulação de seus núcleos de fundamentos teórico-metodológicos da vida social, da formação sócio-histórica da sociedade brasileira e do trabalho profissional no projeto de formação.

\section{III - Algumas consideraç̧ões finais}

As considerações finais se expressam na contextualização das lutas do conjunto CFESS/Cress, Abepss e Enesso, bem como nos desafios atuais postos pela conjuntura de crise estrutural do capital.

\section{a) Consolidação das lutas}

As lutas no período do avanço da precarização do trabalho e do neoliberalismo reafirmaram o PEP por meio de posicionamentos no que se refere a: autonomia e independência das entidades da categoria em relação ao Estado, ao governo e ao patronato; luta contra o neoliberalismo de todos os governos, de 1989 a 2016; defesa dos direitos sociais e trabalhistas historicamente conquistados; luta contra as contrarreformas do Estado, da Previdência Social, sindical, trabalhista e do ensino superior (EAD - Ensino a Distância e mestrados profissionalizantes); em defesa do ensino público, laico, gratuito, universal, de qualidade e socialmente referenciado; contra a criminalização dos movimentos sociais e contra a lei antiterror sancionada em 2016; contra o genocídio da população jovem e negra das periferias dos centros urbanos, dos morros e das favelas; contra a privatização dos serviços públicos; contra a redução dos recursos orçamentários para a saúde, educação, habitação, reforma agrária, urbana e demarcação das terras indígenas e quilombolas; contra a precarização do trabalho e do projeto de lei em tramitação no Senado, referente à terceirização; contra o racismo, a homofobia, a transfobia e a lesbofobia; pela livre orientação sexual; contra o trabalho infantil; contra o ajuste fiscal que impõe medidas de ataque aos trabalhadores ao reduzir direitos sociais e o orçamento para as áreas sociais; luta contra os 55 projetos em tramitação no Congresso Nacional de retirada de direitos dos trabalhadores; apoio ao movimento grevista e à ocupação de fábricas pelo operariado nas indústrias falidas e às grandes mobilizações de junho de 2013 contra o aumento das passagens de ônibus e por saúde, educação, habitação; apoio às grandes mobilizações e ocupações dos estudantes 
secundaristas em São Paulo, Goiás, Rio de Janeiro e Pará na luta pela educação; luta pela reforma agrária e urbana; combate à violência contra a mulher e pela legalização do aborto; retirada das tropas do Haiti; defesa do povo palestino e de imigrantes refugiados.

Um dos desafios atuais consiste ainda em dar continuidade à inserção dos profissionais nos sindicatos por ramos de atividade, na esfera pública por área de contratação e por atividade, como na saúde e previdência, além de atuar como oposição sindical nos sindicatos de resultados, na perspectiva de um sindicalismo autônomo, de base e de lutas; inserção dos profissionais em sindicatos gerais (bancários, gráficos, metalúrgicos) e em outras esferas sócio-ocupacionais em que os profissionais atuam.

A Fenas (Federação Nacional Sindical de Assistentes Sociais), criada em 2000, passou por cima da deliberação unânime da categoria de se organizar sindicalmente no ramo de atividade. A direção dessa entidade e de sindicatos que foram sendo reabertos por ela veio no sentido de disputar, via esses instrumentos, o projeto hegemônico da categoria consubstanciado na Abepss e no conjunto CFESS/Cress. Se durante a primeira década dos anos 2000 a direção da entidade esteve sob a orientação da corrente sindical classista (braço do PCdoB no movimento sindical), a partir de 2004 encontra-se sob a direção da articulação sindical, posição majoritária do PT, na CUT. Após a assunção do governo federal pelo PT em 2003, movimentos sociais de peso, como a CUT e parte da direção do MST, tornaram-se governistas, o que significou um atraso para as massas trabalhadoras do ponto de vista de sua autonomia e independência de classe, o que tem bloqueado o sindicalismo classista.

\section{b) Desafios da conjuntura em 2016 no país}

Termino este artigo em meio a "um golpe de Estado de direita" no Brasil. No dia 17/4/2016, a Câmara dos Deputados votou pela abertura do impeachment da presidente Dilma Rousseff. Ao Congresso Nacional foi facultado o direito de passar por cima de 54 milhões que elegeram a presidente. A maioria dos parlamentares homenageou a família, a religião, a propriedade, e os mais reacionários reverenciaram a ditadura e os torturadores, nem sequer se referindo às "pedaladas fiscais", motivo aparente da abertura de impedimento sem base jurídica de sustentação. Se o impeachment for aprovado no Senado, em 11/5/2016, o país viverá uma situação 
de aprofundamento devastador de ataque aos trabalhadores pelas medidas econômicas, políticas e de avanço do neoconservadorismo que consagrará o golpe de direita (PSDB e PMDB) e partidos a eles aliados contra o princípio democrático da soberania popular. $\mathrm{O}$ golpe atende aos interesses da burguesia, do grande empresariado, da Fiesp, da grande mídia - Rede Globo e jornais e revistas de grande circulação, do monopólio das comunicações, do agronegócio, do Ministério Público, frente a um governo enfraquecido. A grave crise política no país encontra-se diretamente vinculada à crise econômica. O PT, embora tenha implantado em seus treze anos de governo as medidas impostas pelo capital, já não mais interessa aos setores reacionários e de oposição burguesa de direita. É preciso lutar contra o golpe e contra o ajuste fiscal do governo Dilma a partir das reivindicações dos trabalhadores pelas organizações autônomas da classe operária, dos trabalhadores do campo, dos pobres e miseráveis oprimidos que têm sua condição de vida e trabalho cada vez mais deteriorada pela exploração capitalista.

Ao longo dos 37 anos de ruptura com o conservadorismo, o Serviço Social brasileiro se referenciou nos pressupostos do projeto profissional articulado ao projeto societário na direção estratégica emancipatória pela qual nossas entidades têm se orientado, com autonomia e independência de classe, e esse caminho é a possibilidade histórica de uma sociabilidade igualitária e libertária.

\section{Recebido em 3/5/2016 - Aprovado em 13/6/2016}

\section{Referências bibliográficas}

ABRAMIDES, M. B. C. O Projeto Ético-Político do Serviço Social brasileiro. Tese (Doutorado) - Programa de Pós-Graduação em Serviço Social, Pontifícia Universidade Católica, São Paulo, 2006.

; CABRAL, M. S. O novo sindicalismo e o Serviço Social. São Paulo: Cortez, 1995.

; FINGERMANN, T. N.; MAZZEO, S. C. Repensando o trabalho social: a relação entre Estado, instituição e população. 3. ed. São Paulo: Cortez, 1984.

BARROCO, M. L. S. Ética e Serviço Social: fundamentos ontológicos. São Paulo: Cortez, 2001. 
BATISTONI, Maria Rosângela. Oposição sindical metalúrgica de São Paulo: história, organização e lutas. In: ABRAMIDES, M. B. C.; DURIGUETTO, M. L. Movimentos sociais e Serviço Social: uma relação necessária. São Paulo: Cortez, 2014.

IAMAMOTO, M. V.; CARVALHO, R. Relações sociais e Serviço Social no Brasil. São Paulo: Cortez, 1982.

NETTO, J. P. Ditadura e Serviço Social: uma análise do Serviço Social no Brasil pós-64. São Paulo: Cortez, 1991.

. Transformações societárias e Serviço Social: notas para uma análise prospectiva da profissão. Serviço Social \& Sociedade, São Paulo, ano XXIII, n. 50, abr. 1996.

. A construção do Projeto Ético-Político do Serviço Social e a crise contemporânea: capacitação em Serviço Social e Política Social, Módulo 1. Brasília, CEAD/UnB/ABEPSS/ CFESS, 1999.

RAICHELIS, R. Legitimidade popular e poder público. São Paulo: Cortez, 1988.

SINGER, P.; BRANDT, V. C. São Paulo: O povo em movimento. Petrópolis: Vozes, 1980. 